\title{
AN APPROXIMATION APPROACH TO EIGENVALUE INTERVALS FOR SINGULAR BOUNDARY VALUE PROBLEMS WITH SIGN CHANGING NONLINEARITIES
}

\author{
HAishen LÜ, DONAL O’REgAn AND RAVi P. AgARWAL
}

Abstract. This paper presents new existence results for the singular boundary value problem

$$
\left\{\begin{array}{l}
-u^{\prime \prime}=g(t, u)+\lambda h(t, u), t \in(0,1) \\
u(0)=0=u(1) .
\end{array}\right.
$$

In particular our nonlinearity may be singular at $t=0,1$ and $u=0$ and is allowed to change sign. Existence in this paper will be established by obtaining a sequence of upper and lower solutions which in turn will generate a sequence of approximate solutions.

Mathematics subject classification (2000): 34B15.

Key words and phrases: singular boundary value problems, positive solution, upper and lower solution.

\section{REFERENCES}

[1] R. P. Agarwal, D. O'Regan, Singular Differential and Integral Equations with Applications, Kluwer Academic Publishers, 2003.

[2] M. M. Coclite, On a Singular Nonlinear Dirichlet Problem-III, Nonl. Anal., 21, (1993), 547-564.

[3] P. HABETS, F. ZANOLIN, Upper and lower solutions for a generalized Emden-Fower equation, J. Math. Anal. Appl., 181, (1994), 684-700.

[4] V. ANURADHA, D. D. HAI AND R. SHIVIJI, Existence results for superlinear semipositone boundary value problems, Proc. Amer. Math. Soc. 124, (1996), 757-763.

[5] D. D. HAI, R. SHIVAJI, An existence result for a class of superlinear p-Laplacian semipositone systems, Diff. Int. Equ., 14, (2001), 231-240. 